\title{
Entrepreneurial Response to "Bottom-up" Development Strategies in Zimbabwe
}

EMILY CHAMLEE-WRIGHT

Professor of Economics, Beloit College, Beloit, WI 53511, USA

chamlee@beloit.edu

\begin{abstract}
Group lending and business training programs aimed at small-scale entrepreneurs have captured the interest of development scholars, practitioners, and donors since the 1980s. Yet these strategies have not had much impact in the context of urban Zimbabwe. Building upon ethnographic research conducted in Harare, Zimbabwe and insights drawn from the Austrian school of economics, the case is made that group lending and business training programs in urban Zimbabwe fail to meet the needs of most informal entrepreneurs because they offer a poor cultural fit with the target population, and because they are rarely able to cultivate entrepreneurial skills such as innovation and market discovery among their clients.
\end{abstract}

Key Words: Austrian economics, entrepreneurship, microfinance, group lending, informal sector

JEL classification: $\quad$ B53, O17, O18, Z13.

\section{Introduction}

Development literature in the 1980s and nineties marked an important move away from sectoral development planning and towards an emphasis on indigenous entrepreneurship. Rather than emphasizing the state's role in filling the "entrepreneurial gap," many scholars and practitioners began to appreciate the potential for indigenous entrepreneurs to serve as the vehicle for economic development (Boserup 1989, Ayittey 1991, Berger 1991, De Soto 1989). Yet significant barriers, such as the gap between the formal financial sector and the mass of informal entrepreneurs, continue to limit the potential of indigenous entrepreneurship (CGAP 2003).

Attempts to close this gap have suffered a difficult history. Interest rate controls supposedly aimed at relieving the problem only tightened access to scarce credit for informal entrepreneurs (Anderson and Khambata 1985). Loan subsidization and guarantee programs offered through national governments and international aid agencies resulted in high default rates and tended to bypass the target population in favor of elite groups (Anderson and Khambata 1985, Deloitte and Touche 1998, Adams and Von Pischke 1992).

Partly in response to the failure of such initiatives, microlending programs that offer group loans, or so-called "solidarity loans" have gained favor among development scholars, non-governmental organizations (NGOs), international donors, national governments and a few commercial banks. Success stories such as the Grameen Bank in Bangladesh, BancoSol in Bolivia, Bank Rakyat Indonesia (BRI), and the more than 3000 village banks scattered across 25 different countries based on the model pioneered by the Foundation for 
International Community Assistance (FINCA) gave hope that a new paradigm emphasizing bottom-up economic development would provide the solution to sustainable economic development.

Yet, in the Zimbabwean context, such programs have failed to attract the vast majority of informal entrepreneurs. This widespread lack of interest is something of a mystery, given the subsidized interest rates offered by some programs, and the high degree of cooperation informal entrepreneurs practice when engaging in other financial dealings. The argument will be made that solidarity loans, at least as currently practiced in the Zimbabwean context, offer a poor cultural fit, particularly in the face of superior alternatives. The insights of scholars such as F.A. Hayek and others within the Austrian school of economics provide clues as to why indigenous modes of informal finance often provide a more workable solution than programs introduced from the outside.

Many NGOs and state development agencies offer business training as a way to increase the credit worthiness of their clients and improve the chances of long-term business success. There is little doubt that training in basic business skills is an essential first step that many informal entrepreneurs need. But beyond the basic skills of literacy, numeracy, and rudimentary accounting, training programs more often than not adopt a mechanistic approach to business development, perpetuating problems of market saturation and vulnerability to economic volatility in import and export markets and industries dependent on tourism. Again, insights drawn from the Austrian school suggest that a more promising approach to business training would stress the qualities of creativity, innovation, market discovery, and strategies that anticipate likely changes in the economic environment, rather than a formulaic approach to entrepreneurship.

The observations presented here are informed by a series of interviews with Zimbabwean entrepreneurs, development organizations, and commercial banks conducted in 1999. A wide diversity of trades are represented here, and in total, the study includes 150 in-depth interviews with entrepreneurs, the majority of whom are female traders based in the Mbare market area known as the Musika. Also included in the study are interviews with 15 governmental and non-governmental development organizations, and five commercial lending institutions. The present study differs from most attempts to assess the record of bottom up development strategies in that the subjects were chosen at random, not from a pool of program participants. One implication of this approach is that the voices of those who have not been directly affected by such programs are privileged over those who have direct experience with a microlending organization. As Woolcock (1999) suggests, this emphasis is justified in a context where so few informal entrepreneurs choose to participate in such programs. By turning our gaze to the vast majority of traders who do not participate in such programs, we are more likely to gain insight into the reasons why such programs often fail to meet the needs of informal entrepreneurs.

\section{Solidarity Lending in Zimbabwe}

A central feature of many of the most successful microlending programs has been the practice of group lending, or so-called "solidarity loans," in which a group of borrowers jointly guarantees repayment of a loan. Solidarity lending provides protection for the lending 
organization without prohibitively high collateral requirements (Besley and Coate 1995). Further, solidarity loans spread risk among borrowers, creating an incentive to use moral pressure on fellow group members to repay their portion of the loan. Since group members are thought to be in a better position to judge the credit worthiness and enterprise viability than loan officers are, the practice of group lending purportedly allows borrowers to select fellow group members who are the most credit worthy (Ghatak 1999). All of these factors lower the high administrative costs usually associated with lending to entrepreneurs in the informal sector.

Development scholars studying the repayment record and impact of solidarity loans have been optimistic about such an approach. For example, the Grameen Bank boasts a 98 percent loan recovery rate, and is credited with increasing per capita income among its members, enabling greater female participation in the economy, improving agricultural productivity, contributing to improved nutrition and housing, and creating more jobs than any other development organizations in Bangladesh (Wahid 1993, 1994). Similar success stories have been told about programs around the developing world (Hulme and Mosley 1996, Otero 1989, De Silva and Denby 1989).

It should be noted that the microfinance industry has also attracted its share of criticism. Morduch (1999) has suggested, for example, that the success of Grameen Bank and similar programs has been exaggerated, that loan recovery rates do not take into account the risks associated with an expanding portfolio, and that delinquent loans often get counted as "on time" as long as a repayment schedule has been negotiated. Further, the vast majority of microcredit organizations have failed to achieve the long-sought goal of financial sustainability (Yaron 1992). When subsidies on capital are considered, many of the "profits" reported by microfinance organizations are revealed to be losses (Morduch 1999). Further, Woolcock (1999) warns that most scholarship praising microcredit does so uncritically, as it fails to control for other factors that could be contributing to program success. Yet, despite such criticism, development scholars generally remain optimistic about the potential for microfinance programs to lift people out of poverty. ${ }^{1}$

In Zimbabwe, a variety of NGO, government, and commercial institutions have employed alternative lending strategies in order to fill the gap between the informal and formal sectors. The largest and most well known among urban entrepreneurs is the NGO Zambuko Trust. Zambuko Trust boasts a 97 percent loan recovery rate. The organization's stated intention is to lend at a market rate of interest, but because of internal delays in decision-making, the actual rate is often slightly below market.

Other NGOs offering group loans include the Zimbabwe Women's Bureau (ZWB), Dondolo Mudonzvo, and the Indigenous Business Women's Organization (IBWO). Like Zambuko Trust, these NGOs lend to both individuals as well as groups. Yet, unlike Zambuko, when lending to groups, all three organizations generally lend to groups that have formed a business cooperative. IBWO and Dondolo Mudonzvo have experienced relatively low loan recovery rates (approximately 85 percent), while the better-staffed ZWB boasts a 99 percent loan recovery rate. At the time of the interviews, the interest rates these organizations charged on loans ranged from 5-30 percent, well below the then current market rate of 48 percent. All three organizations claimed to have a revolving loan fund, yet given the 
subsidized interest rates they charge, the loan funds require periodic recapitalization from outside sources.

The government development agency SEDCO (Small Enterprise Development Corporation) also offers group loans, though it has proven to be notoriously inefficient. According to an industry study conducted by Deloitte and Touche (1998) 45 percent of SEDCO's 200-member staff were employed at the head office in downtown Harare where few entrepreneurs are likely to venture. The same study found that the organization administered only 1,900 loans in a year' time-less than 10 loans per employee. Further, SEDCO suffers from chronic delinquency. A conservative estimate puts the percentage of loans 90 days past due at 62.2 percent (Deloitte and Touche 1998: 44).

At the time the interviews were conducted, the only commercial bank engaging in group lending was the Commercial Bank of Zimbabwe (CBZ), through its "Community Banking Scheme." CBZ charged a market rate of interest on all its loans, and enjoyed a 99 percent loan recovery rate. Having started operations in 1996, CBZ's Community Banking Scheme was much less well known among informal entrepreneurs relative to other organizations. Among the 150 entrepreneurs interviewed, only four had heard of CBZ's Community Banking Scheme, and none had applied for a loan. Its network of branch offices and its encouragement of savings among small-scale entrepreneurs suggest that awareness of this program is likely to grow, though only 7 of the 116 traders interviewed who held savings accounts had an account with CBZ. The stated goal of CBZ is that the Community Banking Scheme will ultimately be a profit generating division of the bank. As of 1999, the division was just selfsufficient, i.e., was earning enough to pay its own staff and administrative fees, in addition to sustaining its loan fund without having to tap a loan guarantee fund provided by the British government.

Though group lending strategies have gained popularity among Zimbabwean development organizations, the vast majority of entrepreneurs have not benefited from them. Of 150 informal entrepreneurs interviewed, only 17 had applied for a loan. Among these, six were successful in securing a loan. These numbers represent an increase relative to what McPherson found in the 1991 and 1998 Growth and Equity through Microenterprise Investments and Institutions (GEMINI) studies. In 1991, only 0.4 percent of Zimbabwean entrepreneurs in the informal sector received a loan through a formal credit institution, and less than 1 percent from an NGO program (McPherson 1991:27-28). In the 1998 study, McPherson found that among the 1.3 million small- or medium-sized enterprises, the numbers had improved only slightly to 1.4 percent and 1.1 percent, respectively. Overall, 98.8 percent of informal entrepreneurs have never applied for any form of formal credit (McPherson 1998:20, 27).

The most common reasons given why more entrepreneurs do not apply to microlending programs include a lack of awareness about where to apply, a lack of demand for credit (either because the lack of credit was not an effective constraint, or because interest rates were perceived as too high relative to projected earnings), fear of not being able to pay the loan back, and potential borrowers expected not to qualify (Deloitte and Touche 1998). Indeed, these reasons were cited among the entrepreneurs interviewed for the present study. Of the traders who had never bothered to apply to a microlending program, 20.3 percent did not know how to go about applying for a loan, 14.3 percent reported that they did not need a 
loan, 9.8 percent reported that current interest rates were too high, 13.5 percent reported that they feared not being able to repay the loan, and 10.5 percent reported that they assumed they would not qualify.

Yet, these responses only raise more questions. Though many traders are unaware of the specifics of where to apply, the vast majority of entrepreneurs know that such programs exist. (Less than five percent of entrepreneurs indicated that they had never heard of lending programs for small-scale entrepreneurs.) Thus, the question remains as to why they do not pursue the necessary information, if the lack of knowledge is the main obstacle standing in their way. Secondly, though it is understandable that the Zimbabwean macroeconomic and institutional environment makes borrowing against the future a less than attractive option for many people, we are left with the question of why entrepreneurs are not flocking to organizations that offer highly subsidized interest rates. Lastly, though many entrepreneurs do not expect to qualify for a loan as an individual, most are nonetheless aware of the existence of group lending programs that would enable them to bypass ordinary borrowing requirements. This raises the question as to why so few entrepreneurs take advantage of group lending programs in order to avoid the problems of qualifying as an individual.

Contemporary scholars working within the Hayekian tradition, ${ }^{2}$ which emphasizes the evolutionary nature of social rules that help to regulate and extend market activity, provide a clue as to why this might be the case. Boettke (2001), Boettke and Coyne (2003), Chamlee-Wright (1997), De Soto (2000), and Lavoie and Chamlee-Wright (2000), for example, all make a similar point - that social institutions, whether property rights, rules of contract, or rules concerning credit and finance, will all be dependent upon the underlying cultural context if they are to work. Development initiatives that conflict with the cultural context that guides perception and behavior are not likely to be very successful. The interviews conducted for this study lend weight to this line of argument, in that they provide detail as to why Zimbabwean informal entrepreneurs are so often reluctant to participate in microlending programs, particularly those that stress the use of solidarity loans. The interviews suggest that solidarity loans are a poor cultural fit for the Zimbabwean context, and the widespread participation in rotating credit organizations may indicate that entrepreneurs favor informal forms of cooperative strategies over those initiated through the group lending process.

\subsection{Attitudes Regarding Group Lending}

Among the entrepreneurs expressing a preference, 65 percent reported that they would prefer an individual loan to a group loan. Potential moral hazard problems (73 percent) were the most common reasons traders cited for not preferring group loans, but the fear that one of the group members might fall ill or die (14 percent) was another common reason, as were concerns over privacy (10 percent).

When asked why they would prefer an individual loan to a group loan, entrepreneurs typically commented on the lack of trust they would feel towards fellow group members. Comments such as the following were typical, 
Who is to say that everyone else is hardworking? The group lending idea sounds nice. But the problem is that some people are not all that honest. Some may disappear before the loan is paid back, leaving a few people to suffer.

Another trader offered an even more vivid picture of the potential for moral hazard problems.

Group loans would be a disaster [laughter]. This is Mbare, for heaven's sake, not some tiny village where no one can hide. I live here, I know, but so do 80 percent of Harare's ex-convicts! You'd be mad to trust anyone that far. Chances are they'd take the money and run.

Perhaps the attitudes expressed here are not all that surprising, given that most cooperative efforts have the potential for shirking and other moral hazard problems. Yet, such attitudes are surprising given that the vast majority of female entrepreneurs in the informal sector engage in cooperative savings clubs on a regular basis. Seventy-six percent of traders interviewed for the current study engage in some form of ma rounds (literally "the rounds") in which members of a group save a particular amount over a specific time frame, giving the accumulated lump sum to each member in turn (Chamlee-Wright 2002).

Most traders participate in several different clubs simultaneously, each paying off at a different time of the week, month, or year. ${ }^{3}$ This strategy enables traders to maintain the value of their capital by replenishing their stock on a regular basis, maintain control over their financial resources by keeping daily returns out of the hands of their spouse and other family members, and maintain greater discipline over their household and discretionary spending (Chamlee-Wright 2002). Given this level of voluntary cooperative behavior, and the degree to which such arrangements are integral to the survival and capital accumulation strategies most traders employ, it is surprising that they would not also join together in groups for the purposes of borrowing, as they do for the purpose of saving. Below, we will explore some of the key differences between informal savings groups and groups assembled for solidarity lending that may help explain this apparent contradiction.

In addition to moral hazard problems, the fear that a group member might fall ill or die is well founded. Estimates from the World Health Organization put the HIV infection rate at one in every four adult Zimbabweans. Even if the group members are healthy, the death of a family member can nonetheless impair a borrower's ability to repay her portion of a loan. Unexpected illness or death due to AIDS and other diseases is increasingly common, and it is not surprising that entrepreneurs are particularly cautious when it comes to guaranteeing another trader's debt. Comments such as the following are representative.

I would prefer an individual loan. That way, if things are going well, you will be on track with your payments. In a group situation, one of the members may suffer a death in the family and then you become responsible for their payment and the interest charges if they are late. 
A fresh produce trader hoping to leave her trade for one that was more lucrative commented,

With my luck, all the other members of the group would die and then where would I be? I would be stuck paying their debts and I'd never get out of this business.

While life insurance guarantees could address these concerns, those who are the target of microlending programs are the least likely to have the means for purchasing life insurance. ${ }^{4}$ Though some microlending programs use a portion of membership fees to provide an emergency fund to cover the debts of group members who die, such funds do not protect against a group member who loses a family member. Death of a spouse, parent, or extended family member can significantly increase a borrower's financial responsibility to the family. Further, medical and funeral expenses can overwhelm a borrower's ability to repay their portion of a group loan.

Entrepreneurs also cite concerns over privacy as a reason for steering clear of solidarity loans. Though this issue was raised less often than moral hazard concerns or worries over the potential illness or death of other group members, comments such as the following were not uncommon.

I managed to pay back an individual loan with no problem, so I would not want to get involved with something that would cause a lot of talking and finger pointing. I am a very private person, so I don't want to be in a situation where I would get people prying into my private finances.

Again, though traders commonly engage in cooperative savings clubs and other forms of mutual assistance without feeling that it compromises their sense of privacy, the perception among many is that group lending practices are likely to cross that line.

Just as it is important to understand the reasons why so many women prefer individual loans, it is also important to understand the reasons why some traders report they would prefer a group loan. The traders who expressed a preference for group lending often remarked that they preferred solidarity lending because it reduced their own risk, relative to individual lending. As this trader commented,

I would prefer a group loan, so that others can help me to pay it back if I run into trouble. That way I would not lose my property.

While it is true that group loans reduce the need for collateral security, it is the lending institution that reduces its risk, not the borrower. This is particularly true of an entrepreneur who knows herself to be a good risk and who intends to repay the loan. Relative to a situation in which such an entrepreneur borrows only what she personally needs as an individual, the group loan actually increases her burden of risk in that she becomes responsible for the repayment of other group members' loans. In fact, those traders who were most confident in their abilities to repay a loan were more likely to be among those who preferred an individual loan. As this successful trader remarked, 
Since I always pay my debts, I do not see the benefit with these group loans. You become responsible for everyone in the group, but you only get a part of the money. With an individual loan, I am responsible only for myself and I get all of the loan.

On the other hand, if an entrepreneur knows herself to be a bad risk or has a weak commitment to repaying the loan, group lending becomes much more attractive, as is demonstrated by this trader.

If I had a choice, I would prefer an individual loan because dealing with too many people can be a problem. But because I might not be able to pay it back by myself, it may be better for me to get a group loan. Instead of taking your things or putting you in jail, they [the lending organization] make[s] the group pay.

Thus, in an environment in which there is no ideological or cultural reason why entrepreneurs prefer to borrow in groups, borrowers who know themselves to be a good risk and are committed to repayment are much more likely to prefer individual loans. This creates a potential problem for microlending organizations, as those who are most attracted to solidarity loans may have the least commitment to repayment.

\subsection{Attitudes Regarding Cooperative Ventures}

While many scholars recommend the use of solidarity loans (Otero 1989, Konig and Koch 1990, Morewagae, Seemule and Rempel 1995), few such recommendations make reference to the cultural and historical differences among and within countries that might impact the effectiveness of such strategies, or give guidance as to what the appropriate rules of the lending contract might be (Chamlee-Wright 1997:87-98).

A frustration expressed by some microlending program officers was the insistence by donor agencies that a portion of the solidarity loans be made to groups starting a business cooperative. ${ }^{5}$ Given the individualistic character of informal industry in Zimbabwe, such a policy is bound to meet with resistance. Seventy percent of Zimbabwe's informal enterprises are sole proprietorships (McPherson 1991:13). Among the entrepreneurs interviewed for this study, the only partnerships that were formed were with the trader's husband. Even sisters operating from the same stalls reported keeping their business relationships completely separate. No doubt that the restrictions the White minority government placed on indigenous entrepreneurs prior to Independence played a major role in establishing this pattern, as traders were only allowed to trade from the tiny stalls designated by the municipal authority, and were only allowed to form sole proprietorships. Yet no matter the origins of this pattern, the habit of remaining uninvolved in joint business ventures is now an entrenched part of the local culture.

Local NGO staff members know firsthand the problems that are created by insisting that groups engage in a cooperative business venture. But this knowledge is of little use when outside donor agencies dictate the terms of the lending contract when they award their grants to local NGOs. Struggling organizations that depend upon a narrow band of outside financial support are particularly vulnerable to this sort of pressure. As part of an internal evaluation, 
the NGO Dondolo Mudonzvo Credit Scheme conducted an internal study to understand the reasons for an apparent lack of interest in their group lending program. Second only to concerns over moral hazard problems, the most common frustration loan recipients reported was that the profits made from cooperative ventures were shared prematurely, often because of pressure from husbands to get the money earlier rather than later, forcing the cooperative to shut down before it had a chance to succeed. E.S. Sibanda, Director of Dondolo Mudonzvo, argues that the preference among international donors in favor of group lending to business cooperatives is based on a flawed understanding of "African culture."

The myth is that Africans have a tradition of sharing profit. Yes, neighbors will help when a crop needs to be harvested, but at the end of the season, your proceeds are your own. There is a difference between 'solidarity' which we have traditionally had in abundance, and 'cooperatives' that share their proceeds. This is not part of our [Zimbabwean] tradition and culture. The notion of sharing profits is completely alien...

A program officer at the Indigenous Business Women's Organization expressed a similar frustration,

The donor community has a very romantic view of women's cooperatives. But people are reluctant to apply for a loan if they have to join in a business that they do not want to pursue.

Many women do seem to benefit from their involvement in such ventures, reporting that they are more independent, they have become more involved in their communities, and that they are more confident in their ability to make a contribution outside the domestic sphere. Yet, it is not clear that their involvement in cooperatives has made them more productive or gained them any greater economic independence. This is not meant to suggest that cooperative business ventures are necessarily less likely to be financially successful. Rather, the point is that when the cooperative is formed primarily because this is the mechanism for receiving a loan or grant, in a context where there are few cultural resources to support cooperative ventures, we should not be surprised when such ventures more often than not fail economically.

\subsection{Access to Other Forms of Finance}

The limited interest Zimbabwean entrepreneurs have in solidarity loans may be due in part to the fact that they have alternatives for meeting their financing needs. Among those interviewed for this study, 38 percent of traders started their business with the financial assistance of a friend or relative. Of these, most indicated that they had paid their friend or relative back, suggesting that they could anticipate financial assistance from the same person in the future. Personal savings is another principal means by which entrepreneurs finance their business ventures. Fifty-one percent of traders interviewed started their business either in part or entirely from personal resources saved through formal or informal sector employment, petty street trading, or illegal activities such as prostitution. 
The important role personal savings plays in satisfying short-term capital needs only grows once a trader establishes herself in trade and is able to engage in ma rounds. Not only do rounds clubs facilitate savings, they can also be the source of short-term credit. If a trader receives the collected rounds money early in the cycle, she is essentially receiving a short term loan at zero interest. ${ }^{6}$ As most of the microlending programs only offer short term loans for working capital, the amounts borrowers could potentially secure through a microlending program are not necessarily any higher than the amount that can be saved in a typical weekly rounds club. A typical borrower could expect to secure a loan between $Z \$ 1,000$ and $Z \$ 5,000$ from a microlending organization, to be paid over the course of a year. A typical weekly round consisting of seven traders and requiring $Z \$ 450$ per week provides an early recipient a $Z \$ 3,150$ loan, to be paid over the course of seven weeks. Though participants in ma rounds clubs have significantly less time to repay their debt, they avoid the $Z \$ 1,512$ in interest charges they would pay on a $Z \$ 3,150$ loan from an organization like Zambuko Trust, which at the time of this study, was charging an interest rate of 48 percent.

Further, participants in annual or semi-annual rounds can "borrow" against their own savings prior to the official termination date of the round. Some of the larger annual rounds clubs will provide credit in excess of what the trader has contributed. This privilege is generally only extended to trusted members who clearly have the means to repay. Though explicit lending is not a common practice in the Harare markets, more women reported taking a loan from their savings club than reported taking out a loan with a microlending organization.

In addition to savings in ma rounds clubs, 77 percent of traders interviewed also maintain bank accounts in their own name with a formal commercial bank. At the time of the interviews, average bank balances were Z\$2,490 among unmarried female traders and $\mathrm{Z} \$ 13,554$ among married female traders. These figures are surprisingly high given that informal entrepreneurs in the developing world, particularly women, are so often completely alienated from the formal banking sector. Even in the Zimbabwean context, many banks make it difficult for informal entrepreneurs to maintain a savings account. Notoriously long queues, minimum balance and deposit requirements that are out of reach for many traders, business hours that directly conflict with daytime trading, and a business culture that frowns upon customers who operate in the informal sector are just some of the inhibiting factors. Yet, even given these barriers, many informal entrepreneurs make use of the formal banking sector in order to save for business expansion, starting a second business, and other forms of investment.

Informal lenders, or chimbadzo, provide another alternative to formal lending programs, though only six percent of traders interviewed reported that they would consider borrowing from a chimbadzo. Not only are the interest rates well above commercial market rates, often in excess of 100 percent per month, dealings with chimbadzo are seen as immoral and even dangerous. Nevertheless, a few traders who reported that they had no interest in taking out a group loan had availed themselves of the services of a chimbadzo. While most entrepreneurs would not consider borrowing from a chimbadzo a realistic alternative to a lending program, in rare circumstances, it may serve as such. 


\subsection{The Advantages of Indigenous Solutions}

Thus, it is clear that informal entrepreneurs have alternatives to microcredit financing, though the question remains as to why there seems to be such an aversion to group lending practices when other cooperative arrangements are commonplace among these same entrepreneurs. The argument presented here is that group lending, at least as is currently practiced in urban Zimbabwe, clashes with the cultural context on the ground, and that indigenous solutions provide entrepreneurs with a preferable alternative.

It is on this point that the work of F.A. Hayek and the work of those who have followed in this tradition become relevant. A common theme within much of Hayek's body of work is the question of how culture evolves (Lavoie 1990). In his work on the evolution of law, his critique of what he called "Cartesian rationalism" (the notion that the human mind is capable of successfully redesigning human society) and his later critique of socialism, (Hayek 1973, 1988) Hayek argued that the social rules that have evolved over time are responsible for the creation of the extended order in society. By "extended order" Hayek was describing the advanced society's ability to coordinate ever-expanding levels of complexity. Social rules of property, contract, codes of behavior, and the like allow for greater divisions of labor and intellect, and with this greater complexity, more and more people are able to benefit from and make use of knowledge that they themselves do not possess.

The rules that are so crucial to this process are handed down through tradition, teaching, and imitation. The enforcement mechanisms required to make these rules serve a useful function are deeply embedded within the culture, so deeply embedded that most of the time we are unaware that we are even engaging in rule-following behavior. The tacit nature of our knowledge of such rules only serves to help them function more smoothly. The more deeply embedded a system of rules is within a culture, for instance, the less the need for reliance upon outside coercive means of enforcement. People involved in codifying the rules are not creating rules of property or contract or norms of behavior, they are discovering and articulating what has already evolved. If we were to introduce some new set of rules that bore no relationship to the cultural context in which people operate from day-to-day, there would be little chance such a system of rules would bring about the kind of coordination and complexity we see in the extended order. If they are to work, the rules of society must fit well within and must be supported by the cultural context.

A small but growing group of scholars have extended this line of argument in ways that help us to recognize that programs and policies aimed at economic development must also fit well within the cultural context. Boettke (2001), for example, argues that post-communist societies engaged in market reform face not only the hurdle of choosing the right institutions. Such societies are also faced with the question of how to make those institutions take hold in a culture that may provide little support for social institutions like private property rights and contracts. Similarly, Lavoie and Chamlee-Wright (2000) point out that we can not expect cultural practices that inspire hard work and an entrepreneurial mindset in one context will necessarily take hold within another, as the rules and norms of behavior that have evolved over time are likely to become irrelevant once stripped from their original cultural context. In his work documenting the vastness of dormant capital in the developing world, De Soto (2000) argues in the manner of Hayek when he says that the problem of defining property 
rights has already been solved within the informal cultural context. All that policy makers need to do is to discover what those patterns of ownership are-i.e., to articulate in the form of deeds and titles what has already been figured out within the cultural context. Most directly related to the subject at hand, Guinnane's (1994) observations as to why a $19^{\text {th }}$ Century German financial cooperative could not be successfully transplanted to Ireland are based on the fact that the model, which proved so successful in Germany, was poorly suited to the Irish economic and cultural context.

Returning to the Zimbabwean context, the critical difference between the informal cooperative arrangements such as ma rounds clubs and those advanced by microlending programs appears to be the context out of which they emerge. The former stems from embedded cultural practice and correspondingly operates according to a set of well-established, selfperpetuating rules that mesh with the local cultural context. The latter, on the other hand, is perceived as being imposed from outside of the local context, and the rules of operation are seen as less reliable, and frequently violate cultural norms important to maintaining one's status.

Within ma rounds groups, effective forms of monitoring and informal enforcement mechanisms have evolved over time to help minimize the potential for moral hazard problems. For example, at first, a newcomer to the market may find it difficult to find a ma rounds group willing to include her, but as other traders have the opportunity to observe her behavior in the market and assess her ability to pay rounds money regularly and on time, she will eventually be invited to join. In addition to appearing financially stable, a member's participation is contingent on maintaining a reputation as someone who consistently comes to market and avoids conflicts with customers and other traders. Ordinarily, the other members will expect a newcomer to receive the lump sum late in the round, so they can protect themselves and monitor the newcomer's payment pattern. As she builds her reputation as a reliable ma rounds participant, other group members will trust her to receive the lump sum earlier in the round.

When careful monitoring is not enough, informal enforcement mechanisms may also be used. Some clubs impose fines on those who are late with their payments. Virtually all participants reported that if a ma rounds club member were to miss a payment after she had already received the lump sum in that round, she would be banned from participating in future rounds. Gossip serves as an effective form of norm enforcement, as word quickly spreads about a delinquent trader who refuses to make good on her commitments. In order to get a fresh start, she may have to abandon her trade in that area of the market and move to where no one knows her. Given the high costs of changing one's trade, establishing oneself in a new stall, and building a new customer base, losing one's reputation can be very costly, indeed. As such, an overriding ethic of "no excuses" prevails among ma rounds participants, with the expectation that one would sooner borrow the weekly rounds money from a friend or relative than miss a payment.

Microfinance scholars and practitioners usually assume that the same cultural norms employed in informal social networks, such as character assessment, monitoring, norm reinforcement, and enforcement through the threat of ostracization, can be used to support group lending practices (Berger 1989, Deloitte and Touche 1998). It appears, however, that this is not necessarily the case. Though concerns over moral hazard problems were the 
principal reason why traders were not interested in group loans, only 4 of the 150 traders interviewed refused to take part in ma rounds clubs for similar reasons. ${ }^{7}$ One key difference is the degree of repeatability of the groups. Though ma rounds clubs have a clear starting and ending point, most are repeated without interruption. In fact, once a ma rounds club is well-established, there is usually no need to meet as a group unless a member wants to propose a change in the amount being saved or the order in which the lump sum is received. At the beginning of a new round, the trader designated to collect the payments simply circulates among the members on the usual day and time. The ease with which ma rounds clubs are repeated gives force to the social sanctions that are imposed by group members, as the costs of breaking the rules are felt immediately.

Within the context of a solidarity loan, on the other hand, repeating the process is not nearly so easy. A new loan application has to be submitted to and approved by an outside organization. Not only does this process cost entrepreneurs time and money (if an application fee is required), it also costs them in terms of autonomy, as they must seek permission from someone outside the group in order to continue as before. While accountability is essential to any microlending program, the costs associated with these additional requirements may outweigh the perceived benefits, particularly if the entrepreneurs' financing needs can be met equally or nearly as well by participating in a weekly or monthly round. Further, approval can sometimes take many months because of budgeting and staffing shortfalls and bureaucratic inefficiency within the organization. If the microlending program is undercapitalized, as is frequently the case, even qualified borrowers are often turned down for a repeat loan. The uncertainty created by this relative lack of repeatability renders the social sanctions that might be imposed for delinquent behavior much less effective.

A second reason why entrepreneurs eager to take part in informal cooperative arrangements so often resist the notion of group lending may be that they perceive the downside risk to be significantly greater with group lending. In a ma rounds club, group members will suffer a loss if another member fails to repay what she has received, but that loss is internalized immediately. In the case of a solidarity group member failing to pay her portion of the debt, other group members are obligated to future payments until the debt is repaid. Even if the loss to the ma rounds club members is the same as the debt obligation of the solidarity group members, the perception is quite different, as the fears associated with not paying off the debt include confiscation of property, inability to borrow in the future, and possible entanglement in legal proceedings.

In addition to providing more effective safeguards against moral hazard problems and concerns over unanticipated death or illness of a group member, informal savings clubs also seem to avoid violating a traders' sense of privacy and other cultural norms. Even though character assessment is an important form of monitoring within ma rounds clubs, such assessment usually goes no further than observing a trader's behavior, listening for gossip, and in the case of a relatively unknown trader, discreet inquiries. The norms encouraged by most organizations providing solidarity loans, however, favor close scrutiny of group member's personal and business financial records and plans regarding the funds that are to be borrowed.

Such norms make sense in the abstract, in that lending organizations are trying to help borrowers become better informed about the credit worthiness of other group members and 
the viability of their projects. Yet such norms often run rough shod over more pervasive cultural norms. For instance, most group lending programs assume that it is best for everyone in the group to have access to the same information and for everyone to have an equal voice in how things are run. Yet this ignores important cultural norms that pertain to status, respect and privacy. Among Shona ${ }^{8}$ women, for example, it would be highly inappropriate for a younger woman, particularly one who is unmarried or has no children, to insist that she have access to an older woman's personal financial records or give her unsolicited business advice, even if the younger woman has more business experience. Further, class differences among entrepreneurs, such as those conveyed by success in trade, differences in education, or a husband's income or social status are similarly ignored by the egalitarian ethos advanced by most microlending programs.

Within the context of ma rounds clubs, on the other hand, entrepreneurs are able to accommodate the need for power differentials among group members according to social status without inviting abuse of power. Positions of privilege are not arbitrary, but are instead earned through reputation, success in trade, and a history of honest dealings. Group members engage in mutual monitoring, but stop short of violating accepted norms of privacy and autonomy. Again, given that an entrepreneur's financing needs may be met more or less as well by engaging in ma rounds as with a solidarity loan, the lower social costs associated with the former may make it a more attractive alternative.

Overall, the particular cultural and historical context in which Zimbabwean entrepreneurs operate tends to provide little in the way of support for group lending practices. The inability of most programs to effectively address moral hazard concerns, the poor match between local cultural norms and those advanced by microlending organizations, and the availability of alternative forms of finance that do not present these same problems suggest that those microfinance organizations that emphasize group lending and insist upon cooperative ventures may not be advancing the interests of the informal sector as much as they might. Entrepreneurial attitudes regarding group lending practices do not, however, mean that bottom-up strategies for economic development are incapable of working. Rather, the point is that development practitioners and scholars need to look to the entrepreneurs themselves to provide the answers as to what kinds of strategies match their cultural context and therefore will have a better chance of advancing their material circumstances.

\section{Business Training and Technical Assistance Programs}

In addition to group lending, many microfinance organizations seek to promote "grassroots" economic development through training programs designed to help entrepreneurs develop their business skills and technical knowledge of specific industries. Yet, both development scholars and practitioners are divided as to what kinds of services microfinance programs ought to be offering clients beyond micro loans.

Advocates of the "credit plus" approach argue that training programs serve the interest of borrowers - making them more credit worthy through skills development-and microfinance organizations, in that borrowers are more likely to repay loans to organizations they trust and to which they feel a certain degree of loyalty (Morewagae, Seemule and Rempel 1995). Training programs may also provide the microfinance organization greater access 
to the informal sector and create opportunities for microfinance workers to build up specialized knowledge about market conditions, the credit worthiness of entrepreneurs, and the viability of their projects (Konig and Koch 1990). On the other hand, advocates of the "minimalist approach" argue that microlending organizations should serve as a bridge to existing non-profit and for-profit agencies rather than duplicate the same services (Gross and de Silva 2003). The demand for training, technical assistance and social services often overwhelms the resources of the microfinance program and stretches program staff too thin (McKean 1989, Tendler 1989, CGAP 2003). Further, entrepreneurs in the informal sector often have little capacity to absorb the benefits of business training when more basic work, such as literacy and numeracy is needed first (McKean 1989).

Practice among Zimbabwean NGO and parastatal microfinance organizations reflects this split. For example, in addition to offering microlending services, the Zimbabwe Women's Bureau (ZWB) offers courses in literacy and numeracy, conducts workshops on women's empowerment, leadership development, and trains clients in industries such as bee keeping, brick making, soap making, oil pressing, knitting, sewing, and many other income generating activities. On the other hand, NGOs such as Zambuko Trust, ${ }^{9}$ and commercial lending institutions such as the Commercial Bank of Zimbabwe (CBZ), principally offer microlending services without placing much emphasis on training and technical support.

The evidence from Zimbabwe as to which is the more successful approach is mixed. Building on the attitudes expressed by informal entrepreneurs and the experience of Zimbabwean microlending programs, we will explore whether the provision of training and technical assistance is a critical factor in determining repayment rates, increasing the organization's access to the informal sector, and improving the local knowledge of organization staff.

\subsection{Likelihood of Repayment}

Though some organizations such as the Zimbabwe Women's Bureau (ZWB) contend that their extensive outreach is largely responsible for the high repayment rates they enjoy, there is little evidence that this strategy consistently generates these same results among other microlending programs. NGOs such as the Indigenous Business Women's Organization (IBWO), Dondolo Mudonzvo, and state agencies like SEDCO offer extensive training services but have had a far more difficult time recovering loans. While some organizations may explicitly use training and other forms of outreach to improve their repayment rates, other factors may be more important in determining whether entrepreneurs perceive loan repayment as a high priority.

Many program officers complain that in the wake of government initiatives designed to redress past injustices imposed upon indigenous Zimbabweans, borrowers view the loans they receive as an entitlement, which carries little or no financial obligation. Programs like the Social Dimensions Fund, implemented to alleviate the economic disparities imposed by structural adjustment, for example, often fail because borrowers view the loans they receive as restitution for being retrenched (Deloitte and Touche 1998). Even private organizations face this problem when donor institutions insist that their name be attached to any loan that they help to underwrite or guarantee. Borrowers are less likely to repay a loan once they know that the funds have been guaranteed through an international donor or government agency. 
In fact, program officers at the Commercial Bank of Zimbabwe's Community Banking Division suggest that one of the reasons CBZ has been successful in recovering almost all of its loans is that they have not made use of the guaranteed loan fund provided by the British Department for International Development (DFID), nor do they tell borrowers that such a fund even exists. When donors insist that such information be disclosed to borrowers, they undermine the organization's efforts to instill a sense of contractual obligation.

Such problems are only exacerbated when lending programs fail to follow up on debt collection or do not enforce their own rules that prohibit future borrowing by those who failed to pay a previous loan in full and on time. Those programs that are the most successful in terms of loan repayment rates are those that clearly convey to borrowers the obligation such a loan entails, and can credibly commit to following their own procedures for debt collection (Deloitte and Touche 1998, See also Woolcock 1999 for case studies of institutional failure in which microfinance organizations were unable to enforce their own rules of repayment).

In other words, those programs that come closest to mimicking the ethos established among informal savings clubs, i.e., "no excuses for not paying," and back this ethos with swift and certain enforcement mechanisms tend to have the highest repayment rates. However, an organization that does not have the resources it needs to follow up on debt collection not only undermines its own credibility with borrowers, it tends to muddy the waters for other microlending programs, as borrowers assume that a relaxed approach to debt collection is the norm. This may be one reason why even previously successful program like the Grameen Bank are experiencing greater difficulties. As Morduch (1999) suggests, the drive to expand the micro-lending program has been accompanied by less strict monitoring and greater flexibility in dealing with loan recipients who have trouble repaying their loans on time. This sort of flexibility may be undermining the enforcement mechanisms that were the source of the program's initial success.

Another factor determining an entrepreneur's level of commitment to loan repayment is whether the organization is perceived as stable, i.e., does the borrower trust that the organization will be around in the future to offer another loan? (Deloitte and Touche 1998). One entrepreneur interviewed for this study had taken out a loan with the NGO Zimbabwe Women's Finance Trust (ZWFT), but she eventually stopped paying on it. She reported that,

Every time I went by the office, no one was there. I thought they had closed for good... I was disappointed because they had promised they would recommend me for a bigger loan with Barclay's [Bank]. My husband and I want to start a cleaning business...

She went on to explain that in order to secure a loan with Barclay's Small Business Division, a borrower must first have successfully repaid at least two loans with ZWFT. When it appeared to her that ZWFT would not be in a position to recommend her to the commercial bank, she lost the motivation to repay her original loan. Though ZWFT was in fact still in operation, inconsistent follow-up and a lack of administrative presence in the area office diminished the direct pressure on the borrower to repay. Inconsistent follow-up contact by microfinance organizations undermines one of the important attributes microfinance programs are supposed to convey-that the promise of future loans will discipline current borrowers to repay their current loan (Besley 1995). 
Lastly, a borrower's commitment to loan repayment may be undermined if the microfinance organization is perceived as engaging in unfair practices. For example, the Indigenous Business Women's Organization (IBWO) conducted a vigorous outreach program to solicit members. In return for the required membership fees, the organization promised to establish a revolving loan fund, from which members could eventually borrow. Several small groups of entrepreneurs reported that after joining IBWO, they applied for solidarity loans but were turned down. They reported that the loan officer told them to return later in the year because there was not yet enough money to make loans from the revolving fund. Though it is understandable that it takes time to build the critical mass needed to establish a revolving fund, IBWO's unwillingness or inability to offer the loans soon after the membership fees had been collected contradicted the rules most women would find appropriate given their experience with informal rounds clubs. As this frustrated entrepreneur expressed,

I will have nothing to do with them again. They are nothing but cheats... When they refused to lend us the money, I demanded my money [membership fee] back-but they refused. This is unfair!

Even if IBWO secured the funding necessary to start lending out of the revolving loan fund, they will be remembered by many as the organization that "took the money and ran," and therefore may lack the moral authority to require prompt and full repayment.

Some microlending programs do rely upon training programs to build trust and loyalty among borrowers. Yet this is not the only way to proceed, nor is an organization likely to capitalize on the goodwill it does build through training if it fails to follow up on delinquent loans, fails to enforce its own rules, or makes promises to entrepreneurs it can not keep. Though adequate funding is a necessary condition for meeting these requirements, it is certainly not sufficient, as even a well-funded organization that is poorly managed can easily destroy the positive and negative enforcement mechanisms essential for high rates of loan repayment.

\subsection{Access to the Informal Sector}

Though training services may or may not assist in loan recovery, it is fairly clear that training programs serve as an important form of outreach for many organizations. In particular, organizations that serve the poorest and least educated participants in the informal sector depend upon their training programs to provide the first building blocks that will bridge the distance between the informal and formal sectors. The Zimbabwe Women's Bureau (ZWB), for example, which conducts extensive training and other forms of outreach, enjoys a high reputation among entrepreneurs who have started their business with the help of the organization. In fact, among entrepreneurs, ZWB is better known for its training programs than its lending programs. Program officers at the ZWB view the organization as a bridge to more narrowly defined financial institutions such as Zambuko Trust or CBZ. As such, the training fills an important gap by cultivating a level of comfort for working within an organizational structure, along with providing practical skills and information. Yet, such support is expensive to provide, often does not yield results for many years, and unlike a 
more narrowly defined lending program, has no obvious source of revenue other than donor support. Even though the program officers at ZWB say that their hope is to develop into a self-sustaining organization that does not rely on outside support, it is unlikely that they will be able to continue to serve their current client base if they do.

While training and technical assistance programs afford some organizations greater access to the informal sector, merely offering such services is no guarantee that the organization will reach small-scale entrepreneurs. SEDCO, for example, boasts an array of extension services that surpasses even what the Zimbabwe Women's Bureau provides, yet the poor (or nonexistent) reputation it has among informal entrepreneurs closely resembles that of the Zimbabwe Development Bank (ZDB), which conducts virtually no outreach. What seems to matter most in accessing the informal sector is not necessarily the provision of training services, but the organizational culture at work within the microlending program. Though SEDCO and ZDB differ in terms of the services they offer, their organizational culture is strikingly similar. It is not simply that the two organizations are "uninviting," it is as though there has been a conscious effort to alienate informal entrepreneurs. Pictured on SEDCO's small business loan brochure is a drawing of a man (with remarkably Caucasian features) in a three-piece business suit. Behind him and on his desk are impressive looking graphs and charts, presumably indicating the growth of his business-hardly an image with which informal sector entrepreneurs (particularly women) are likely to identify. The main offices are housed in large corporate buildings, populated by people in business suits, with guards and other gate keepers stationed at every access point. On the outer door of the SEDCO offices, a sign reading "NO HAWKERS" is prominently displayed in bright red lettering. If by chance informal entrepreneurs do hear about the programs offered by ZDB or SEDCO, most will never apply, as the application procedures for a small business loan are as rigorous as a traditional business loan, requiring city registration and operating licenses, lease agreements, proof of demand for services, extensive business records, and proof of business equity.

The question arises whether the lack of outreach conducted by such organizations is a hurdle standing in the way of their success in meeting the needs of informal entrepreneurs, or if their lack of outreach is an indicator that the true interests of such organizations lie elsewhere. Commercial institutions may create microlending divisions not because they see this segment of the market as a potential source of revenue, but simply as a way to gain political favor. The problem within state organizations like SEDCO is more entrenched, in that their source of funding as an agency has little to do with serving small-scale enterprises and far more to do with successfully rent seeking National Party officials. Given the organizational culture operating within such programs, it is unlikely that any business training or technical assistance programs they do develop will provide much access to the informal sector.

Organizations such as Zambuko Trust and CBZ provide little in the way of free training and have instead focused their outreach efforts on improving access to loan officers. By establishing local field offices and by providing loan officers with motorbikes in order to visit clients at their home or place of business, both these organizations contend that they are meeting the needs of informal entrepreneurs more directly. It should be noted however, that these innovative initiatives are modest in scope. Loan officers do not in general actively 
recruit interest in the lending programs they represent or make attempts to educate large numbers of entrepreneurs about the availability of such programs. The training that they do offer is provided for a fee, further limiting the field of entrepreneurs who are likely to participate. Organizations that pursue these more moderate forms of outreach tend to be those that lend to entrepreneurs with a proven track record in business and who have some level of financial stability coming into the lending program. The benefit of this strategy is that it acts as a sorting mechanism. By engaging in only moderate outreach and charging for services, they distinguish their organization from social service oriented NGOs. Further, entrepreneurs who are of severely limited means or experience tend to assume that they will not qualify for a loan with organizations that conduct limited forms of outreach and therefore do not apply. On the other hand, those who have had enough experience in the market to know how lending programs work in general, and are willing and able to pay for business training courses are already indicating to the lending institution that they are a good risk.

If, as an organization, the goal is to provide a mediating structure so as to link the very poor to formal financial institutions, a vigorous outreach initiative, including training and technical support appears to be vital. Yet, it is likely that given this goal, such organizations are less likely to be self-sustaining, and will continue to be donor-driven institutions in the long run. If the goal is to evolve into a self-sustaining microfinance institution, the best model seems to be to provide moderate forms of outreach so that capable entrepreneurs are aware of the organization, its programs, and how to contact members of the staff, but not so much support as to imply that everyone who applies is ready to receive a loan. ${ }^{10}$ It should be noted that using outreach, or lack of outreach, as a sorting mechanism is a blunt instrument, however, and will not always send the right message to the right entrepreneurs. Among the entrepreneurs interviewed for this study were desperately poor traders who could not understand why organizations like Zambuko Trust would not give them a loan, just as there were relatively successful entrepreneurs who had never considered applying for a loan because they assumed that they would not qualify. Yet in an environment in which there is limited understanding among potential borrowers of how lending programs work and what qualifications are necessary, a blunt instrument may be better than none at all.

\subsection{Improving the Local Knowledge of NGO Staff}

As NGO staff gain experience in technical assistance programs, they are likely to learn about the details of the specific trade and the individual entrepreneurs being trained. The question is whether such knowledge is of a sort that will enable them to more effectively advise borrowers in running a successful business and more effectively evaluate which entrepreneurs are the best candidates for a loan.

On the one hand, by targeting loans and services to a narrow range of enterprises, staff members do begin to develop specialized knowledge of particular industries (Tendler 1989). But the downside of this strategy is that as organizations gain expertise in a few areas, they tend to emphasize the technical aspects of the production process rather than the skills of entrepreneurship that emphasize innovation and the discovery of new market opportunities. Many projects that aim at training women in particular crafts and trades, such as batik, 
sewing, or crocheting lead to heavily saturated markets as the same training programs are duplicated over and over again. Upon graduating from such programs, entrepreneurs more often than not have little or no marketing strategy or access to markets outside their own immediate neighborhoods.

The notion that training programs help microlending staff gain specialized knowledge often confuses technical know-how with entrepreneurial insight. While training programs can help microlending staff gain specialized knowledge in batik making, for example, it is no guarantee that it will lead to entrepreneurial insight, such as when it is time to start another batik business verses some other kind of craft, or what kinds of designs and fabrics are likely to attract the most customers, or where such goods are selling and how to get the goods there at the least cost. Acquiring the technical knowledge needed to advise entrepreneurs on how to create specific objects is relatively simple compared to the more critical forms of specialized knowledge, i.e., entrepreneurial knowledge that is cultivated by engaging in the market process. By offering training in a narrow range of productive activities, NGOs may be doing more harm than good by emphasizing cookie cutter models of entrepreneurship rather than fostering experimentation and innovation among individual entrepreneurs.

A potential advantage of developing industry-specific training programs may be that staff members are in a better position to judge the credit worthiness of borrowers and the viability of their projects when they observe and learn more about entrepreneurs enrolled in training programs. Level of commitment to the training process may be one indicator of a potential borrower's work ethic and how serious she is about seeing her business succeed. Yet, a strong work ethic is not necessarily an indicator of a strong commitment to repay a loan. Further, while the training program could help staff members identify the most technically proficient trainees, technical proficiency does not necessarily mean that the borrower is able to make sound entrepreneurial judgments. Lastly, the advantages in terms of increased knowledge by NGO staff will have little impact if the people doing the training are not in close communication with the people making the lending decisions. Though training programs have the potential to increase the knowledge of NGO staff, an entrepreneur's savings history and previous track record in business may still serve as the lending institution's most important indicators as to whether a trader is likely to repay her loan and is capable of exercising good entrepreneurial judgment.

\section{Conclusion}

Given the dismal record interest rate controls, loan subsidization and loan guarantee programs have had in the developing world, the choice to pursue more "bottom-up" strategies for economic development is certainly reasonable. In that they directly address the needs of informal entrepreneurs, solidarity lending and training programs represent important advances in the field of economic development. Yet such strategies are never implemented within a cultural vacuum. Before seizing upon group loans or training programs as a panacea for fostering economic development, attention must be given to the specific historical and cultural dynamics that are at work within any given context. The present study illustrates the resistance solidarity lending and cooperative production practices might meet within a specific cultural context, and suggests that NGOs, donor agencies, and commercial 
organizations will be more successful in meeting their goals and those of entrepreneurs if they are prepared to adjust to the local culture rather than expect the culture to adapt to the development strategy.

Seeking a good cultural fit suggests that rather than importing a model developed in an entirely different context, a more fruitful approach may lie in building off of local practices, such as informal ma rounds savings clubs. Because informal structures emerge out of the local context, the enforcement mechanisms that have evolved over time complement cultural norms regarding status, authority, and privacy. Further, the comparative ease with which informal agreements are repeated tends to give the enforcement mechanisms that have evolved greater force. Though training programs and other forms of direct outreach may help an organization improve its access to the informal sector and help it to maintain high loan recovery rates, microlending organizations may be even better served by mimicking the ethos established in the informal structures. Rather than impose norms that reflect an egalitarian ideology, for example, microlending organizations may be better off adopting rules that respect local norms regarding social status. Further, popular perception of group lending programs would likely be enhanced if the approval process for repeat loans approached the ease and low cost with which ma rounds clubs are ordinarily renewed. Most importantly, given the widespread concern over moral hazard problems, group lending programs are best served if they can credibly commit to their own rules regarding loan repayment. It may be, however, that organizations simply can not mimic the ethos practiced within informal structures, in which case, microlending organizations may be better off abandoning the group lending strategy altogether.

As the field of economic development has turned towards more bottom-up strategies that directly target informal entrepreneurs, microlending institutions have had to play a dual role- one that is primarily civic in nature and one that is driven by market considerations. There are clear benefits to microlending organizations taking on this dual mission. First, such a mission recognizes that capital-poor entrepreneurs have the potential to put developing nations on a sustainable path towards economic development and it recognizes that in order to realize this potential, such entrepreneurs need assistance in overcoming the barriers that stand in their way. Second, microlending programs that have a clear sense of their dual role are more likely to serve as effective mediating structures that bridge the gap between the informal market and the formal commercial sector.

Yet this dual role is fraught with challenges. Because such organizations do not fully operate within a market context, they are limited in their ability to determine whether their programs and practices are truly meeting the needs of their clients. Organizations that offer their services for free or at subsidized rates do not receive the feedback that would be offered in a commercial context. This lack of feedback tends to make the organization less flexible and less responsive to what the market is calling for. Absent the discovery process that can only be gleaned within the context of the market, organizations are more likely to emphasize and pass along technical knowledge rather than focus on entrepreneurial skills of innovation, creativity, and alertness to opportunities that will reduce costs or increase yield. Further, to the extent that microlending organizations are shielded from the discipline of the market, income generating projects often turn into welfare programs dependent on the organization rather than self-sustaining profitable enterprises. 
In order to address these challenges, microlending organizations need to assess whether the business training and technical assistance programs they initiate have commercial viability, i.e., whether there is demand for the services the program provides and whether entrepreneurs are in a position to cover the costs of providing those services. If the organization can establish that such programs are needed in order to move a given population towards self-sufficiency, yet the recipients are unable to pay for the services provided, the civic role microlending organizations have been playing in connecting the poorest and least skilled members of the informal sector to government and international donor resources is appropriate. Yet if the same approach is used with entrepreneurs who are in a position to be treated as clients rather than as recipients of aid, the organization is missing an opportunity to further advance informal entrepreneurs' migration into the formal commercial sector, as well as an opportunity as an organization to be more responsive to market realities.

\section{Acknowledgments}

I would like to thank my research assistants and interpreters Bertha Mashonga, Jacqui Gutuza, Carol Muranzi, Kuda Usore, and Florence Nyakabau of the University of Zimbabwe, without whom the primary research for this paper could not have been accomplished.

\section{Notes}

1. Part of this optimism stems from the apparent advantage microfinance programs have relative to other poverty alleviation instruments. Schreiner (2003) and Pitt and Khandker (1998), for example, argue that Grameen generates a net social return on donor investment, while many other well-known poverty alleviation programs generate a net drain on social resources.

2. See, in particular, Hayek $(1973,1988)$.

3. The average daily round has ten members and requires a contribution of approximately $\mathrm{Z} \$ 50$ per day. The average weekly round has seven members and requires a $Z \$ 450$ contribution per week. Annual and semiannual rounds require only a minimum payment (usually daily) of $Z \$ 10-Z \$ 20$, though traders can increase their contribution to any level they choose. During the period these data were collected, the average exchange rate was Z\$38/US\$1.

4. Microcredit is only one among many services the microfinance industry might provide. The poor also have significant unmet demand for insurance, pension, savings, consumer credit, and other financial services. See CGAP (2000)

5. In the years following Independence in 1980, the Zimbabwean government also played a part in promoting the idea of business cooperatives, as it represented a way to provide direct support to local businesses without violating its Leftist ideological stance. Such grants are still offered, though few entrepreneurs seek them out.

6. Those receiving the funds late in the cycle are essentially earning a negative interest rate on their savings, yet the advantages of participating, in particular the ability to keep their resources out of the hands of their spouse while avoiding time consuming trips to the bank, tend to outweigh the costs.

7. The principal reasons why some traders did not engage in ma rounds were either that they were too poor to make regular payments, or that they were so successful in trade that the amounts saved in most ma rounds clubs were too small to make a difference in their financial planning.

8. The Shona are the dominant ethno-linguistic group in Zimbabwe.

9. Zambuko Trust does offer an eight week training course to its "Trust Banks," usually constituting groups of 15 to 30 illiterate or semi-literate women interested in seeking a loan. After the eight week course, Zambuko considers lending small amounts on a mutually guaranteed basis. But the main focus of Zambuko's efforts lies with more established entrepreneurs from whom they do not require more than a one day orientation session. 
10. The cases presented here echo the conclusions of Hulme and Mosley (1996) who argue that the impact of credit programs is negligible among the poorest groups of borrowers, and therefore, these groups ought to be offered access to social service programs, but not necessarily credit. Further, they argue that financial sustainability seems to be critical, as the programs that have the greatest impact are those that are at or near a level of self-sustainability. Morduch (1999), however, points to problems with the data presented within the Hulme and Mosley studies, and cautions that sweeping conclusions should not drawn from them.

\section{References}

Adams, D. and Von Pischke, J. D. (1992) “Microenterprise Credit Programs: Déjà vu.” World Development, 20(10): 1463-1470.

Anderson, D. and Khambata, F. (1985) "Financing Small-Scale Industry and Agriculture in Developing Countries: The Merits and Limitations of 'Commercial' Policies." Economic Development and Cultural Change, 33(2): 349-371.

Ayittey, G. (1991) Indigenous African Institutions. New York: Transnational Publishers.

Berger, B. (1991) The Culture of Entrepreneurship. San Francisco: ICS Press.

Berger, M. (1989) "Giving Women Credit: The Strengths and Limitations of Credit as a Tool for Alleviating Poverty.” World Development, 17(7): 1017-1032.

Besley, T. and Coate, S. (1995) "Group Lending, Repayment Incentives, and Social Collateral.” Journal of Economic Development, 46.

Boettke, P. (2001) "Why Culture Matters: Economics, Politics, and the Imprint of History," Calculation and Coordination: Essays on Socialism and Transitional Political Economy. London: Routledge.

Boettke, P. and Coyne, C. J. (2003) "Entrepreneurship and Development: Cause or Consequence?" Advances in Austrian Economics, 6: 67-87.

Boserup, E. (1989) Women's Role in Economic Development. London: Earthscan Publications.

CGAP (2002) "Why Donors Need to Understand Product Development." Donor Brief, No. 8, November, World Bank, Washington DC.

CGAP (2003) CGAP Phase III Strategy 2003-2008: Building Financial Systems that Work for the Poor, World Bank, Washington DC.

Chamlee-Wright, E. (1997) The Cultural Foundations of Economic Development: Urban Female Entrepreneurship in Ghana. London: Routledge.

Chamlee-Wright, E. (2002) "Savings and Accumulation Strategies of Urban Market Women in Harare, Zimbabwe." Economic Development and Cultural Change, 50(4).

Deloitte and Touche (1998) "Conditions for Access to Financial Services for Micro and Small-Scale Entrepreneurs." Discussion Paper for Zimbabwe National Chamber of Commerce.

De Silva, D. and Denby, N. (1989) Banking the Unbankable: Bringing Credit to the Poor. London: Horizon India Books.

De Soto, H. (1989) The Other Path: The Invisible Revolution in the Third World. New York: Harper and Row.

De Soto, H. (2000) The Mystery of Capital: Why Capitalism Triumphs in the West and Fails Everywhere Else. New York: Basic Books.

Ghatak, M. (1999) “Group Lending, Local Information, and Peer Selection.” Journal of Development Economics, 60(1): 27-50.

Gross, A. and de Silva, S. (2003) "Microfinance and Rural Finance Operational Notes for World Bank Staff." No. 1 (August) Washington DC: World Bank.

Guinnane, T. (1994) “A Failed Institutional Transplant: Raiffeisen's Credit Cooperatives in Ireland, 1894-1914.” Explorations in Economic History, 31(1): 38-61.

Hayek, F. A. (1973) Law, Legislation, and Liberty, Vol. 1. Chicago: University of Chicago Press.

Hayek, F. A. (1988) The Fatal Conceit: The Errors of Socialism. Chicago: University of Chicago Press.

Hulme, D. and Mosley, P. (1996) Finance Against Poverty, Vol. 1. London: Routledge.

Konig, W. and Kotch, M. (1990) "External Financing of Microenterprises in LDCs: Lessons from Colombia," Savings and Development, 14(3): 233-245. 
Lavoie, D. (1990) "Introduction to F.A. Hayek's Theory of Cultural Evolution: Market and Cultural Processes as Spontaneous Orders." Cultural Dynamics, 3(1): 1-9.

Lavoie, D. and Chamlee-Wright, E. (2000) Culture and Enterprise: The Development, Representation, and Morality of Business. London: Routledge.

McKean, C. S. (1989) "Training and Technical Assistance for Small and Microbusinessses: A Review of their Effectiveness and Implications for Women.” In: M. Berger and M. Buvinic (Eds.).

McPherson, M. A. (1991, 1998) Micro and Small-Scale Enterprises in Zimbabwe: Results of a Country-Wide Survey. Washington DC: USAID.

Morduch, J. (1999) “The Microfinance Promise.” Journal of Economic Literature, 37(4): 1569-1614.

Morewagae, B. S., Seemule, M., and Rempel, H. (1995) "Access to Credit for Non-Formal Microenterprises in Botswana." The Journal of Development Studies, 31(3): 481-504.

Otero, M. (1989) "Solidarity Group Programs: A Working Methodology for Enhancing the Economic Activities of Women in the Informal Sector." In: M. Berger and M. Buvinic (Eds.).

Pitt, M. and Khandker, S. (1998) “The Impact of Group-Based Credit Programs on Poor Households in Bangladesh: Does the Gender of Participants Matter?" Journal of Political Economy, 106(5).

Schreiner, M. (2003a) “A Cost-Effectiveness Analysis of the Grameen Bank of Bangladesh.” Development Policy Review, 21.

Tendler, J. (1989) “What Ever Happened to Poverty Alleviation?” World Development, 17(7): 1033-1044.

Wahid, Abu N. M. (1993) The Grameen Bank: Poverty Relief in Bangladesh. Boulder: Westview Press.

Wahid, Abu N. M. (1994) "The Grameen Bank and Poverty Alleviation in Bangladesh: Theory, Evidence and Limitations." The American Journal of Economics and Sociology, (53)1: 1-15.

Woolcock, M. J. V. (1999) "Learning From Failures in Microfinance: What Unsuccessful Cases Tell Us About How Group-Based Programs Work.” The American Journal of Economics and Sociology, 58(1): 17-43.

Yaron, J. (1992) “Successful Rural Financial Institutions.” World Bank Discussion Papers, No. 150. Washington DC: World Bank. 